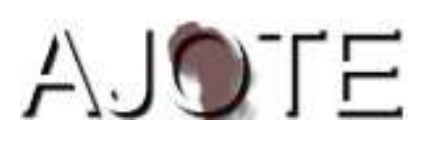

African Journal of Teacher Education

ISSN 1916-7822. A Journal of Spread Corporation

Volume 8

2019

Pages 53-68

\title{
Prevalence of Psychoactive Substance Use Among Undergraduate Students at Chirunga College, Malawi.
}

\author{
Kuyokwa John ${ }^{1}$ \\ Chiziwa Symon ${ }^{2} \&$ Semphere Nertha ${ }^{3}$ \\ Malawi.
}

\begin{abstract}
The purpose of this study was to determine the prevalence of use of psychoactive substances among undergraduate students at Chirunga College in Malawi. The study was guided by Ajzen's Theory of Planned Behaviour. Mixed research methodologies were used, in which both quantitative and qualitative research methodologies were employed in data generation and analysis. SPSSv20 and Excel were used in quantitative data analysis and qualitative data was analyzed thematically. The study involved 147 participants and the findings revealed that (34\%) of students used psychoactive substances. It recommends that undergraduate students who use psychoactive substances like any other user of these substances, require help. Accordingly, as an institution of higher learning, Chirunga College has to take the necessary steps to address this problem; including introducing counselling and psychotherapy services at the institution.
\end{abstract}

Keywords: Psychoactive substance abuse, use, depression, undergraduate students, Chirunga College, Malawi.

\section{Background of Study}

The study sought to explore the prevalence of the anti-social behaviours of psychoactive substance use among undergraduate students of diverse ethnic backgrounds at Chirunga

\footnotetext{
${ }^{1}$ Malawi College of Health Sciences. Email: johnkuyokwa@gmail.com

2 University of Malawi. Email: schiziwa9@gmail.com

${ }^{3}$ University of Malawi. Email: nsemphere@cc.ac.mw
} 
College in Malawi. Studies conducted in different countries have shown that undergraduate university students abuse psychoactive substances (Esposito-Smythers \& Spirito, 2004; Garlow et al., 2007). Most of these undergraduate students are either adolescents or young adults. Hence for the purposes of this study, undergraduate students will operationally comprise these categories. Adolescence is a period of human development when young people start to develop the adult's physiological, psychological, sociological, and emotional functions (Ellis, 2004). Agreeing with Ellis (2004), the adolescence age is a period from 12 to 20 years and young adulthood a period from 21 to 25 years. This study concentrated on adolescents aged between 15 to 20 years and young adults aged between 21 to 25 years.

College years can be a challenging time, and some college students experience depression as a result of academic pressure, relationships, family expectations, financial pressure, and identity development (Eisenberg, Gollust, Golberstein \& Hefner, 2007). Due to different challenges that students face when in college, some develop age inappropriate behaviours which are contrary to prevailing norms for social conduct. This is referred to as anti-social behaviours (DSM-4). The anti-social behaviours include psychoactive substance use, social dysfunction (suicidal attempts, aggressiveness) and racism (Esposito-Smythers \& Spirito, 2004).

This study focused on anti-social behaviours. It was concerned with the abuse of alcohol, cannabis, coffee/caffeine, valium, un-prescribed drugs and tobacco; a too common situation when some students start feeling stressed and depressed (Garlow, 2002). Effects of substance abuse include increased suicide risk in adolescents and young adults (EspositoSmythers and Spirito, 2004; Fowler et al., 1986; \&Garlow, 2002). Lo, Monge, Howell, and Cheng (2013) looked at the association between use of psychoactive substances and mental health problems among American college students and found alcohol abuse/dependence and the nonmedical use of prescription drugs to be associated with relatively serious mental illness and with lack of health care.

\section{Statement of the Problem}

The Government of Malawi recognizes that no health system is complete without due consideration of the mental health needs of the population (Mhp, 2000). In order to address mental health issues like substance abuse, the Government of Malawi formulated the first national mental health policy in the year 2000 (Mhp, 2000). However, little is in the policy on the need to screen students for substance use and on how to help those identified to need help. 
Extant research has also concentrated on looking at substance abuse among adult population in general; though some observations in Malawi have associated substance abuse with adolescent and young adult depression (Garlow et al., 2007).

Nonetheless, little research has been done to investigate the prevalence of anti-social behaviours among undergraduate students in Malawi's institutions of high learning. University students have to adapt to various psychosocial changes in coping with academic and social demands during training for their professional careers. Some reports have suggested that substance abuse among Malawian undergraduate students is a problem that needs to be further investigated (Yuriy Zverev, 2014). It is clear that students' performance in universities is negatively affected by use of psychoactive substances and that it impairs their academic achievement (Mazur, Tabak, Dzielska, Wąż \& Oblacińska, 2016). Hence, the present study seeks to fill this gap by exploring the prevalence of psychoactive substance use among undergraduate students at an institution of higher learning in Malawi, the Chirunga College.

\section{Main research question}

What is the prevalence of anti-social behaviours (psychoactive substance use) among undergraduate students in Malawi, using Chirunga College as a case study?

\section{Subsidiary research questions were:}

i. What is the relationship between psychoactive substance use and depression among undergraduate students?

ii. Does peer pressure have an impact on psychoactive substance use among undergraduate students?

iii. Why do undergraduate students use psychoactive substances?

\section{Review of Literature}

\section{The prevalence of psychoactive substance ab/use among adolescents and young adult students}

Jennings' US study (2000) revealed a prevalence of anti-social behaviours among US students Many reasons are suggested as to why adolescents pickup anti-social behaviours like taking un-prescribed drugs, smoking cannabis and using alcohol. Some studies indicate family and peer influence to be the strongest motivators of drug and alcohol use in teens and 
they have further reported that despite a general reduction in alcohol use among adolescents and young adults over the past decade, heavy alcohol use remains a big problem, particularly in college populations where heavy episodic or binge drinking is especially prevalent (Kandel, 1999; Johnston, O’Malley, Bachman, \& Schulenberg, 2013) and Chirunga undergraduate students have shown a similar pattern. Research has suggested that alcohol and marijuana ab/use in the university tend to be adopted as a mechanism to cope with stress of work (Thomas et al., 2006; O'Malley, \& Johnston, 2002). A report in United States of America, 2007 by National Center on Addiction and Substance Abuse (CASA) at Columbia University, showed high alcohol abuse level of nearly 50\% (3.8 million) of all full-time college students who have had binge drinking (defined as five or more drinks on one occasion in the previous 30 days) or had abused drugs during each month of that year.

The rate of drinking among US college students noticeably climbed up between 1993 and 2005 and the rate of riskier drinking also increased substantially (CASA, 2007). The number of US college students who reported binge drinking three or more times increased by 16\% from 1993 to 2001 (CASA, 2007). Recent studies have also revealed high 51.3\%, prevalence of frequent binge drinking among college students in France (Tavolacci et al, 2016). Also, narly one quarter of US college students were three times more likely to meet the diagnostic criteria for substance abuse or dependence than the general population (CASA, 2007). Two years later a similar study on prevalence of substance use disorders and aspects of the help-seeking process among university students reported that public university students in the US have substance use disorders and have poor self-help seeking behaviours (Caldeira et al, 2009). Because little or no studies of similar nature is known for Malawi the current study wants to examine whether a similar trend occurs and collate data on it.

The consequences of this high rate of alcohol abuse among college students are profound, including the prevalence of alcohol-related sexual assault or date rape and unprotected sex (Hingson, Heeren, Zakocs, Kopstein, \& Wechsler, 2002).

\section{Theoretical Framework}

Icek Ajzen's (1991) theory of planned behaviour provides a framework for studying the prevalence of use of psychoactive substances among undergraduate students. Ajzen proposed that the occurrence of a specific behaviour is determined by intentions, attitudes, and subjective norms. Ajzen's theory further proposes that there are three beliefs that are predictive of an individual's behaviour or behavioural outcomes. These are the individual's 
attitude towards the behaviour, the subjective norm of the behavior and the individual's perceived control of the behavior. This theory of planned behavior has been used by different scholars to explain the behaviors of college students in marketing, and in health and to assess college students' beliefs (Parikh \& Servaty-Seib, 2013).This theory is relevant for this study because it explains causes of unhealthy behaviours among college students. The theory explains that social processes must also be taken into account in evaluating human behaviour. A weakness of the theory is that it is not specific to targeted behaviours or groups hence it is difficult to generalize to other specific behaviours. In the context of this study, the theory allows the researcher to consider the college environment as playing an important role in shaping the behavior of students. College students with depressive symptoms at Chirunga College, Malawi can have their condition alleviated if proper support systems are put in place.

\section{Theoretical Application}

Behaviour in this case is the undergraduate student's feelings of depression or use of psychoactive substances, while Intention are thoughts about when to use psychoactive substances which could be secondary to the feelings of depression. Attitudes are a student's overall evaluation of the behaviour.

Applying the theory of Planned Behaviour to this study would imply that the undergraduate student's experience of substance abuse constitutes the behaviour in questions; while thoughts about when to use psychoactive substances, which could be secondary to the feelings of depression, constitutes the intention. Finally, the students' evaluation of the behaviour of using psychoactive substance, that is, his or her beliefs about the need to use it, is based on the benefit of using it, which might be to reduce depressive symptoms based on the students' beliefs, would constitutes attitudes. The next section attempts to highlight an application of the theory to our research.

Subjective norms; Ajzen (1991) defines Subjective norms as one's own estimate of the social pressure to perform or not perform the target behaviour. In his theory, he assumed that Subjective norms has two components that work in interaction, these are: the person's beliefs about how other people who may be in some way important to them, would like them to behave and how the person's view of himself/herself affects his/her perceptions. In this case student's peer expectations of use of psychoactive substances and student's perceptions of use of psychoactive substances affect the act of using psychoactive substances. For example, 
a friend who suggests going out to drink or taking psychoactive substance can make the subject student use it without him/her having made a considered decision. A student's feeling of depression can also make him/her perceive that the best way of managing depression is to use psychoactive substances.

Perceived behavioural control is the extent to which a person feels able to enact the behaviour (Ajzen, 1991). A person's belief of perceived behavioural control has an impact on how s/he responds to a certain behavior. Ajzens' theory assumes two aspects to perceived behavioural control, one being how much power a person has control over the behaviour and the other, how confident a person feels about being able to perform or not perform the behavior. The first would be the extent to which a student has control over anti-social behaviours when peers or friends urge him or her to be involved in psychoactive substance abuse. The second is the student's ability to make a decision whether or not to involve him/herself in the behaviour. It is determined by the students' powers to say no to friends who want him/her to be involved in anti-social behaviour. Therefore, a student's beliefs of perceived behavioural control plays an important role in decision making process in order to be involved in anti-social behaviours or resist peer influence.

\section{Research Design and Methodology}

The study used mixed methods research design. Both quantitative and qualitative research designs were employed in data collection and analysis. The research design was selected because the research questions of the study required different data collection strategies, hence different research methods. The use of mixed methodology also allowed triangulation and converging of findings. It also helped to clarify the results, discovering the contradiction, as well as extending the breadth of the inquiry (Creswell, 2003).

We have adopted a triangulation design with both qualitative and quantitative data collected almost simultaneously to take advantage of strengths of either method and at the same time offset the weaknesses of the other (MacMillan, 2004). All our study participants were deemed to be rich with information. During data analysis, quantitative and qualitative methods were used sequentially, taking into account the advantages of the triangulation design ensuring that issues identified through the quantitative data analysis were triangulated using the qualitative data analysis.

A hundred and forty-six (146) participants were enrolled in the study, represented as follows; $96(64.6 \%)$ males, 51(34.7\%) females, \& 1(0.7\%) other sexual orientation (Other 
Prevalence of Psychoactive Substance Use Among Undergraduate Students at Chirunga College, Malawi.

sexual orientation represents sexual minority groups) respectively. The bar graph below shows the details.

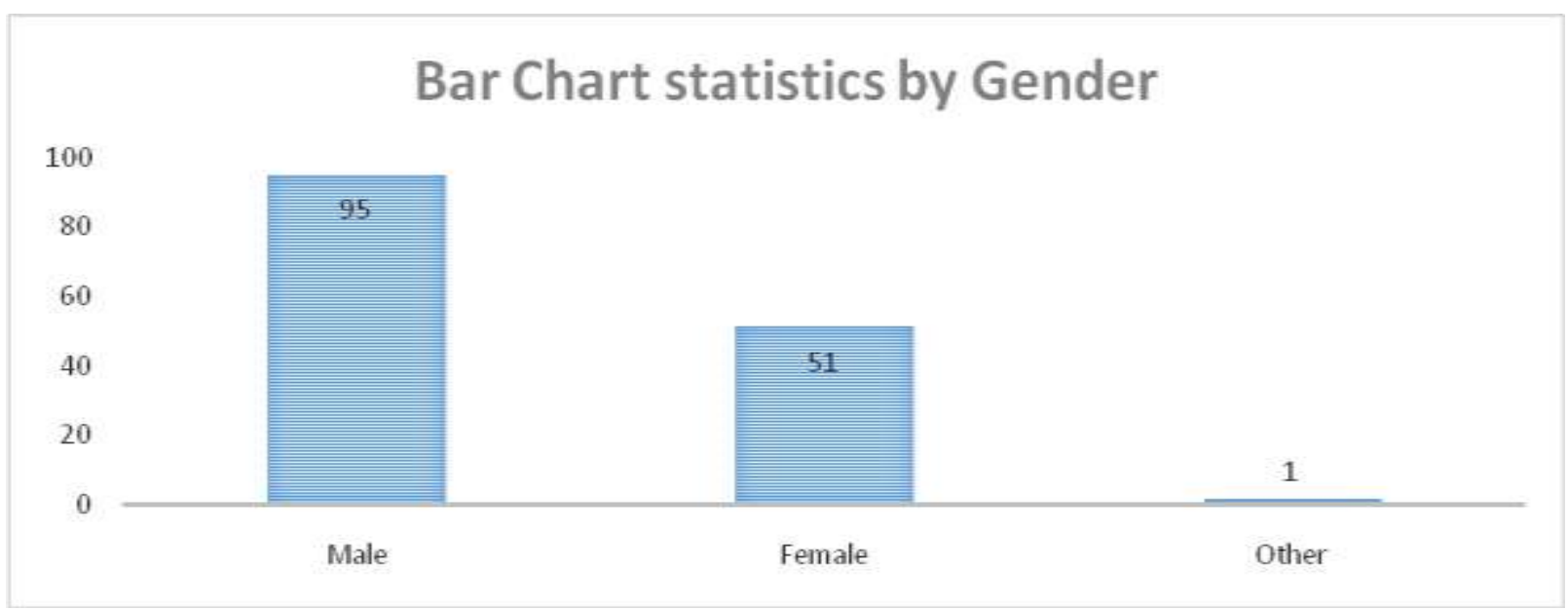

Figure 1: demographic statistics

The graph shows that they were more male students than female students for study.

\section{Study population}

The selection of our study population was based on the Chirunga college records (2016). These records indicate that 2507 students were aged between 15 to 25 Years. Out of the total; 1135 were aged 15 to $20(45.3 \%)$ and 1371 were aged 21 to $25(54.7 \%)$.

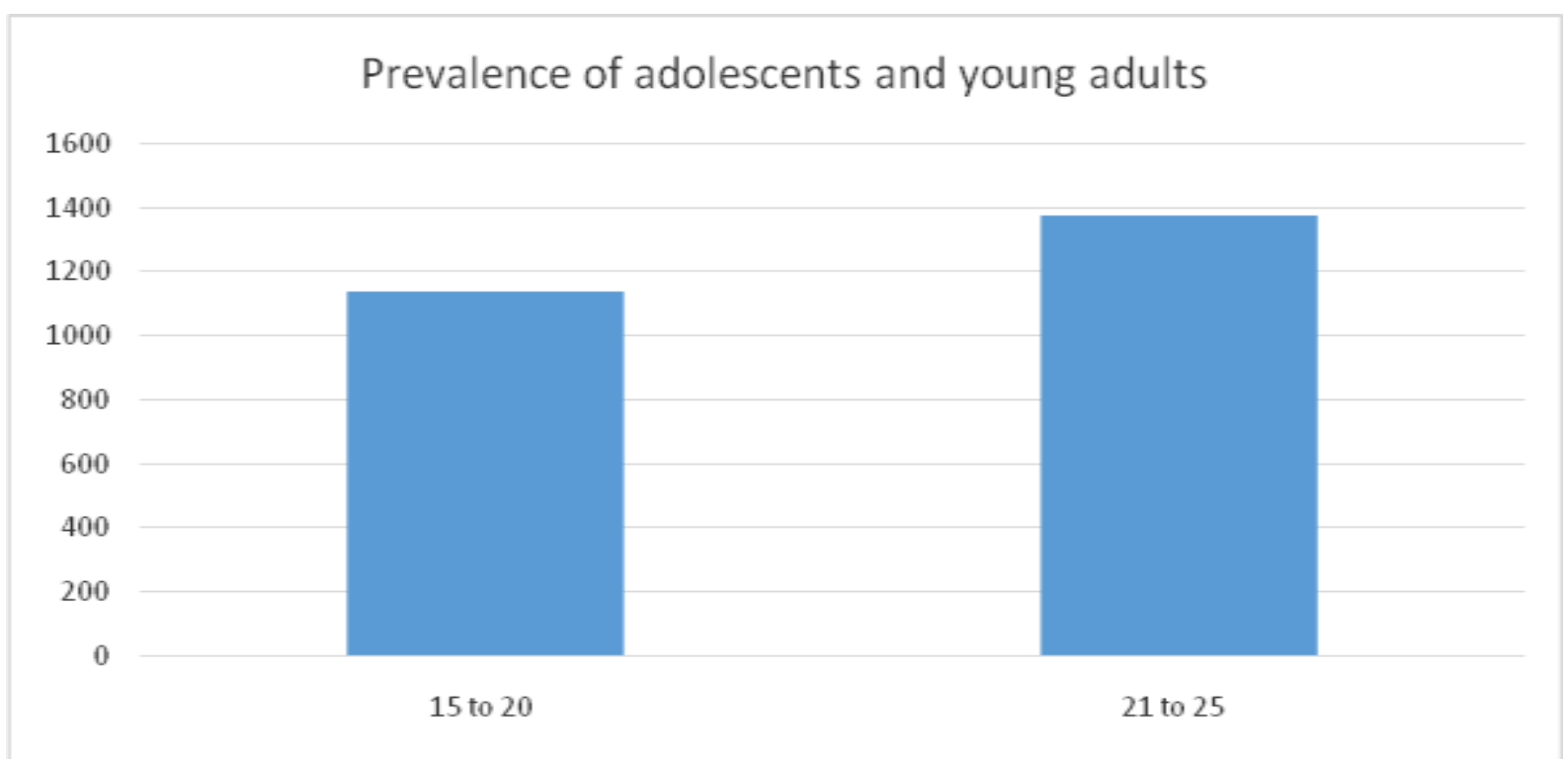

Figure: 2: General adolescents and young adult student population at the college.

This bar graph shows that majority of the study participants were aged between 21 to 25 years than those who were aged between 15 to 20 years at the college campus. 


\section{Demographics of targeted study participants}

The age range of the targeted study participants was from 15 to 25 years and the sub-ranges were as follows; 15 to 20 years were $96(65.3 \%)$, and 21 to 25 years were $51(34.7 \%)$.

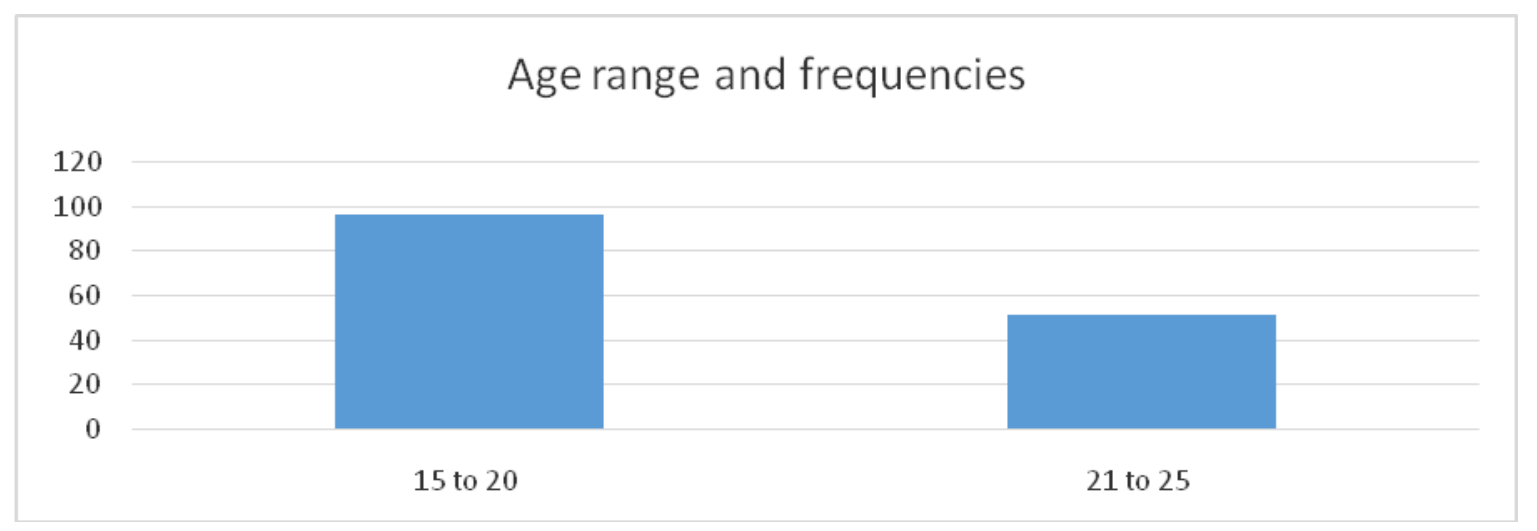

Figure 3: demographic statistics

This bar graph shows that the majority of the study participants were aged between 15 to 20 years.

\section{Academic year, marital status, and mode of scholarship}

The majority of the research participants were first year students 52 (35.4\%), followed by second year students 50 (34.0\%), then fourth year students $28(19.0 \%)$ and finally third year students, 17 (11.6\%). Most of the study participants were single 141 (95.9\%), while those who were separated were $3(2.0 \%)$, and married 3 (2.0\%), respectively. Most of the study participants were government sponsored students 84 (57.1\%), while private students were 63 $(42.9 \%)$.

\section{Data Collection and Instrumentation}

The participants involved in this study were the 2015 / 2016 cohort of undergraduate students attending Chirunga College. Data was collected using an adapted Patient Health Questionnaire (PHQ-9), a WHO validated questionnaire used to diagnose depression in humans in a community - also validated for Malawi. Since PHQ-9 is commonly used in local communities and not in clinics, the researchers adopted it so that they could use it to assess prevalence of and diagnose depression among undergraduate students community. PHQ-9 would enable us associate the feelings of depression and use of psychoactive substances among students. 
The structured questionnaire was designed to include demographic details, $P H Q-9$ Depression Scale, names of psychoactive substances that are commonly abused and respondents were asked to tick against appropriate response. In addition, respondents were provided with space where they could describe the reasons why they decided to use psychoactive substances and how the psychoactive substance use affected their academic performance. Researchers and three enumerators distributed the study questionnaires randomly to the participants, which were then self-administered by the students. The responses that were obtained were coded for data analysis. Some thematic responses were appropriately quoted.

\section{Data Processing and Analysis}

Quantitative data analysis was done using SPSS and excel while Qualitative data analysis had been done thematically. While these two analyses were done independently of each other, the interpretation was not. In this study, quantitative analysis informed the qualitative analysis and conversely, the quantitative analysis elaborated on the qualitative analysis. This approach provided further insights and points for triangulation and helped to provide a clear meaning to the study findings (Cresswell, 2009; McMillan, 2004; Rus-Eft \&Preskill, 2001). Descriptive summaries of quantitative data were based on the statistical means and were presented graphically and as relevant data tabulations.

\section{Discussion of Findings}

The question that guided this study was: what is the prevalence of use of psychoactive substances among the undergraduate students?

\section{The prevalence of anti-social behaviours (use of psychoactive substances)}

Figure 4: Prevalence of psychoactive substance use among participants

\begin{tabular}{|c|l|l|}
\hline Use of psychoactive substances & Frequency & Percent \\
\hline Yes & 50 & 34.0 \\
No & 97 & 66.0 \\
\hline Total & & 100.0 \\
\hline
\end{tabular}


Figure 4 indicates that $34 \%$ of participants were using psychoactive substances while $66 \%$ were not. While a high percentage of participants were not using psychoactive substances, the percentage involved was still high enough to cause concern amongst college administrators and education stakeholders. Although slightly lower, this is somewhat similar to the $45 \%$ rate that Hingson, et al., (2002) found in their study of use of psychoactive substances among undergraduate students in different universities in the U.S.

\section{Psychoactive substance ab/use and depression}

The study shows that 35 participants (24\%) who engaged in substance abuse had depression while 15 participants (10\%) who also engaged in substance abuse did not have depression. (See figure 5). These results show that not everyone engaging in psychoactive substance abuse had depression. On the other hand, 59 participants (40\%) who did not engage in substance abuse had depression while 38 participants (26\%) who did not engage in substance abuse did not have depression. From these results, it is clear that the presence of depression is not dependent on use or non-use of drugs. Students are prone to depression because of the academic pressure they undergo in higher education and not necessarily because they used psychoactive substances or not.

Figure 5: Use of psychoactive substances versus Depression

\begin{tabular}{|l|l|l|l|}
\hline $\begin{array}{l}\text { Use of psychoactive } \\
\text { substances with } \\
\text { depression }\end{array}$ & $\begin{array}{l}\text { Use of psychoactive } \\
\text { substances without } \\
\text { depression }\end{array}$ & $\begin{array}{l}\text { No Use of } \\
\text { psychoactive } \\
\text { substances with } \\
\text { depression }\end{array}$ & $\begin{array}{l}\text { No Use of } \\
\text { psychoactive } \\
\text { substances and No } \\
\text { depression }\end{array}$ \\
\hline $35 \mathbf{( 2 4 \% )}$ & $15(\mathbf{1 0 \% )}$ & $59(\mathbf{4 0 \% )}$ & $38(\mathbf{2 6 \% )}$ \\
\hline
\end{tabular}

This means that participants had other means of coping with depression apart from resorting to substance abuse.

Ajzen (1991) argues that a person's attitudes towards something has an impact on the outcome of behaviour. As mentioned earlier on, he also considered attitude to have two components which work together: beliefs about consequences of the behavior and the corresponding positive or negative judgements about the features of the behavior. In this case 
students' cultural belief about engaging in use of psychoactive substances could have an influence on the type of psychoactive substance to use and not necessarily as a result of students' feelings of depression and the student's evaluation of use of psychoactive substances as a way of managing depressive feelings has an influence of what type of psychoactive substances to use.

\section{Regarding friends using psychoactive substances.}

The study reveals that $100(68 \%)$ participants had friends who were using psychoactive substances while $47(31.97 \%$ ) of participants did not have friends who were using psychoactive substances.

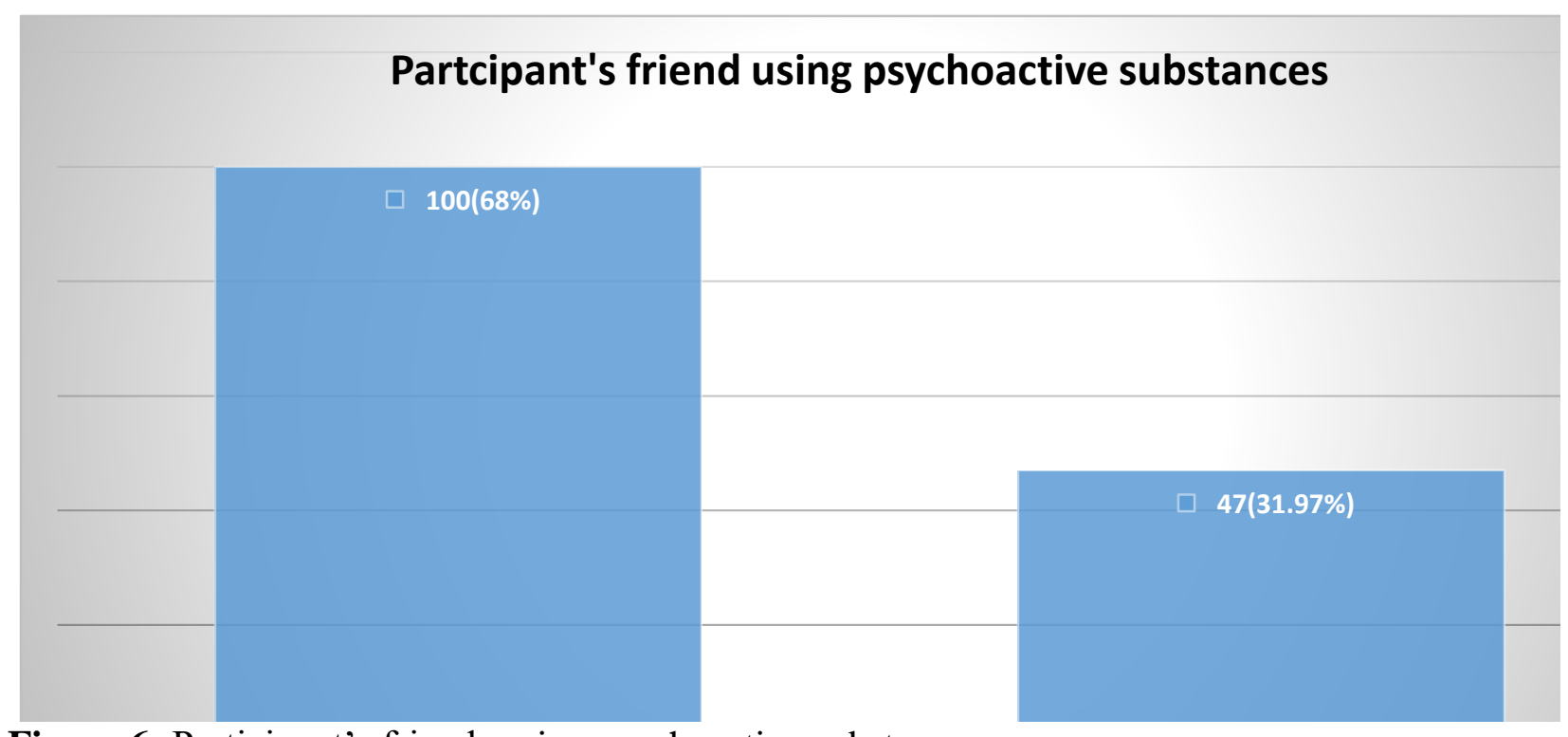

Figure 6: Participant's friends using psychoactive substances.

Figure 6 shows that 100 participants had friends who were using psychoactive substances while 47 participants had friends who were not using psychoactive substances. Thus, the study participants had more friends who were using psychoactive substances.

The data from our research study has revealed that there is a possibility that some of the study's participants came under the influence of peers to use psychoactive substances. This shows that there is to some extent the possibility that students' use of psychoactive substances is influenced by peers. 


\subsubsection{Reason for using psychoactive substances}

This study reveals that there are different reasons why college undergraduate students use psychoactive substances.

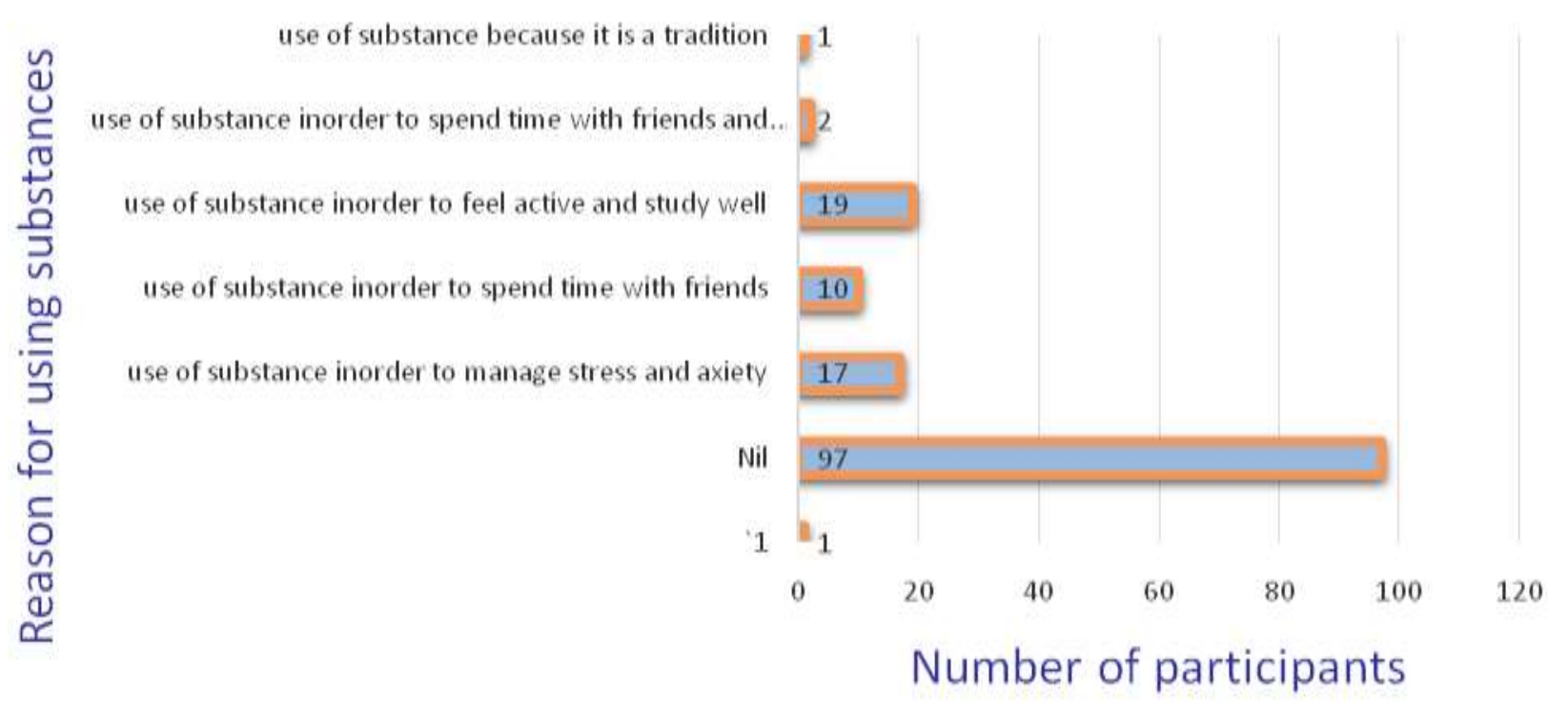

Figure 7: Participant's Reasons for using psychoactive substances

The following are reasons which participants provided for using psychoactive substances. The study revealed that majority, 66\% of participants (97) provided no reason for using psychoactive substance. $12.9 \%$ participants (19) used them to feel active and study well, $11.6 \%$ (17) to manage stress and anxiety, $6.8 \%$ (10) participants to socialize with friends, and $1.4 \%$ (2) both to spend time with friends and study actively. One participant $(0.7 \%)$ used psychoactive substances as a cultural tradition, and 1 participant $(0.7 \%)$ was not sure why s/he used it.

One of the touching written responses include the following:

Participant "I use coffee in order to stay awake and study so that I get a very good grade. However, drinking coffee doesn't have any effect with my interactions with other people that is as far as I can notice”.

These responses demonstrate the Theory of Planned Behaviour's component of the person's view of himself/herself affects his/her perceptions. This agrees with this participants' thinking as the participant is perceiving that using psychoactive substance like coffee will make him 
stay awake and study hard and hence get a good grade. Therefore, from the above participant's response, Ajzen (1991) Theory of Planned Behavior clearly demonstrates student's reasons for using psychoactive substances.

\section{Study Implications}

The study has revealed that undergraduate students at Chirunga College suffer from depression and use of psychoactive substance problems. Therefore, counseling services should be provided to undergraduate learners with the problems of depression and use of psychoactive substances at the college. However, it is important to note that use of psychoactive substances is not the only symptom of depression. As the study revealed, even those who are not actively using psychoactive substances are at the risk of being depressed due to other challenges including pressure of work at the college.

\section{Recommendations}

The study recommends the formulation of a policy to include counseling services in higher education institutions and an appropriate student counseling service referral system in Malawi. The University of Malawi should establish a Counseling clinic at the college where students with depression and those use of psychoactive substances problems can access counseling services. Lecturers should be trained to identify symptoms of depression among students so that they can identify them early and refer them appropriately. Students should be encouraged to go for expert routine screening for depression, when they have feelings of depression so that they could receive timely help.

\section{References}

American Psychiatric Association. (2000). Diagnostic and statistical manual of mental disorders (4th ed.). Washington, DC: Author.

Azjen, I.(1991). Theory of planned behaviours. Organisational Behaviour and Human Decision Processes, 50, p. 179-211.

Burns, N. and Groove, S. K. (2005). Practice of Nurisng Research, conduct, critique and utilization. Philadelphia W.D Saunders.

Chirunga College. (2016). Chirunga College Student's Statistical records. Zomba 
(unpublished).

Creswell, J. W. (2003). Research design: Qualitative, quantitative, and mixed methods approaches (2nd Ed.). Thousand Oaks: Sage Publications.

Creswell, J.W. (2009). Research design: Qualitative, quantitative, and mixed methods approaches (3rd Ed.). London: Sage Publications.

Caldeira KM, Kasperski SJ, Sharma E, Vincent KB, O'Grady KE, Wish ED, Arria AM (2009). College students rarely seek help despite serious substance use problems. J Subst Abuse Treat. 2009 Dec; 37(4):368-78. doi:10.1016/j.jsat.2009.04.005. Epub 2009 Jun 23.

Eisenberg, D., Sarah Gollust, B,A., Ezra Golberstein, B,A., and Hefner, J, L. (2007). Prevalence and Correlates of Depression, Anxiety, and Suicidality Among University Students, American Journal of Orthopsychiatry.

Ellis, B. J. (2004). Timing of pubertal maturation in girls: An integrated life history approach. Psychological Bulletin, 130, 920 -958. Doi: 10.1037/ 0033-2909.130.6.920.

Esposito-Smythers, C,1. \& Spirito, A. (2004). Adolescent substance use and suicidal behavior: a review with implications for treatment research. Alcohol Clin Exp Res. 2004 May;28(5 Suppl):77S-88S.

Fowler, R. C., Rich, C.L., \& Young, D. (1986). San Diego Suicide Study, II: substance abuse in young cases. Arch Gen Psychiatry. 43:962-965.

Garlow, S. J., Rosenberg J, Moore, J. D., Haas A. P., Koestner B., Hendin H., Nemeroff C.B. (2007). Depression, desperation, and suicidal ideation in college students: results from the American foundation for suicide prevention college screening project at Emory University. Depress Anxiety 25:482-488. Published online 8 June 2007 in Wiley InterScience (www. interscience.wiley.com). DOI 10.1002/da.20321.

Garlow, S. J. (2002). Age, gender, and ethnicity differences in patterns of cocaine and ethanol use preceding suicide. Am J Psychiatry.159:615-619.

Hingson, R., Heeren, T, Zakocs R, Kopstein, A., \& Wechsler, H. (2002). Magnitude of alcohol-related mortality and morbidity among U.S. college students ages 18AJUIt Vol. ४ (LUUY), pp. bs - 6૪ 
24. Journal of Studies on Alcohol. 63(2):136-144.

Kandel, D., J. Johnson, H. Bird, M. Weissman, S., Goodman, B., Lahey, D. Regier, and Schwab-stone, M. (1999): "Psychiatric Comorbidity Among Adolescents with Substance Use Disorders: Findings from the MECA Study," Journal of the American Academy of Child \& Adolescent Psychiatry. Volume 38, Issue 6, June 1999, Pages 693-699.

Jennings J, Pearson, G., Harris, M.(2000). Implementing and maintaining school-based mental health services in a large, urban school district. J Sch Health. 2000 May; 70(5):201-5.

Johnston, L. D., O'Malley, P. M., Miech, R. A.,. Bachman, J. G., \& Schulenberg, J. E. (2014). MONITORING FUTURE 2013 Overview - Monitoring the Future. www.monitoringthefuture.org/pubs/monographs/mtf-overview2013.pdf.

McMillan, J. H. (2004). Educational research: Fundamentals for the consumer (4 York: Pearson.

Mhp (Mental health policy), (2000). The National Mental Health Policy. Ministry of Health. Lilongwe.

Mazur, J, Tabak, I, Dzielska, A., Wąż ,K., Oblacińska, A .(2016). The Relationship between Multiple Substance Use, Perceived Academic Achievements, and Selected SocioDemographic Factors in a Polish Adolescent Sample. Int J Environ Res Public Health. 2016 Dec 21;13(12). pii: E1264. doi: 10.3390/ijerph13121264.

National Center on Addiction and Substance Abuse at Columbia University (CASA) (2007).

Wasting the Best and the Brightest: Substance Abuse at America's Colleges and Universities. CASA; New York: 2007

Nwoke, M.B., Kalu T, U., Ogba, N., Ugwu C., (2012). Family and Peer influence on Drug Use among Nigerian Youth. International Journal of Research in Arts and Social Sciences Vol 4.

Lo, C, C., Monge, A.N., Howell, R, J., and Cheng, T, C. (2013). The role of mental illness in 
alcohol abuse and prescription drug misuse: gender-specific analysis of college students. J Psychoactive Drugs. 2013 Jan-Mar;45(1):39-47.

O'Malley, P.M, and Johnston. D. (2002). Epidemiology of alcohol and other drug use among American college students. Journal of Studies on Alcohol.

Parikh, S, J., \& Servaty-Seib, H, L. (2013). College students' beliefs about supporting a grieving peer. Death Stud. 2013 Aug;37(7):653-69.

Patient Health Questionnaire-9 (PHQ-9). https://www.phqscreeners.com/sites/g/files/g10049256/f/...PHQ-9_English.pdf

Russ-Eft, D., \& Preskill, H. (2001). Evaluation in organizations. New York: Basic Books.

Thomas, M.R., Shanafelt, T, D., Dyrbye, L, N. (2006). Systematic review of depression, anxiety, and other indicators of psychological distress among U.S. and Canadian medical students. Acad Med.; 81:354-373.

Tavolacci MP, Boerg E, Richard L, Meyrignac G, Dechelotte P, Ladner J (2016). Prevalence of binge drinking and associated behaviours among 3286 college students in France. BMC Public Health. 2016 Feb 23;16:178. doi: 10.1186/s12889-016-2863-x.

Wechsler, H., Lee, J. E., Nelson. T. F., Kuo, H. (2002). Underage college students' drinking behavior, access to alcohol, and the influence of deterrence policies: Findings from the Harvard School of Public Health college alcohol study. Journal of American College Health, 50, 223-236.

Yuriy, Z. (2014). Problem drinking among university students in Malawi. Article in Collegium antropologicum · April 2008. 